\title{
La política turística y la intervención del Estado. El caso de Argentina*
}

\author{
Erica Schenkel, ${ }^{* *}$ Fernando Almeida García ${ }^{* * *}$
}

Perfiles Latinoamericanos | Artículo vol. 23 | núm. 46 | 2015

pp. $197-221$

\section{Resumen}

La escasez de análisis politológicos en torno al turismo se explica por la primacía de la perspectiva económica que concibe al fenómeno como una simple actividad de consumo ligado al sector privado. Sin embargo, la ciencia política es una pieza fundamental para comprender el turismo, dado que proporciona conceptos e instrumentos metodológicos que enriquecen su estudio. Desde esta perspectiva, se analiza la evolución de la política turística argentina teniendo como referencia los modelos de producción económico-turísticos. Se identifican las principales funciones que adquiere el turismo como asunto público en el país siguiendo la evolución de un contexto social, económico y político particular estructurado con base en cánones internacionales vigentes. Finalmente, se aporta un modelo de desarrollo socioeconómico basado en el turismo.

\begin{abstract}
The very limited of political science analysis on tourism is explained by the primacy of the economic outlook that conceives tourism phenomenon as a simple consumer activity linked to private sector. However, political science is a cornerstone for understanding tourism, provides concepts and methodological tools that enhance the study of tourism. From this approach, we analyze the evolution of Argentina tourism policy taking as a reference production models economic-tourist. In this sense, we identify the main functions that takes tourism as a public issue in the country determined by the evolution of a social, economic and political context, which is structured according to existing international patterns. We point out the existence of an economic development model based on tourism.
\end{abstract}

Palabras clave: política turística, política pública, modelos productivos, funciones públicas, intervención, Argentina.

Keywords: tourism policy, public policy, product models, public functions, intervention, Argentina.

* La investigación contiene avances de la tesis doctoral que se encuentra en proceso de redacción por la primera autora en el marco del Doctorado en Ciencias Sociales de la Universidad Nacional de Cuyo. Este trabajo también forma parte del proyecto de I+D+i del Gobierno Español, "Geografías de la crisis: análisis de los territorios urbano-turísticos de las Islas Baleares, Costa del Sol y principales destinos turísticos del Caribe" (CSO2012-30840).

** Doctoranda en Ciencias Sociales con mención en las Ciencias Políticas y la Administración Pública en la Universidad Nacional de Cuyo de Mendoza (Argentina). Está adscrita al Consejo Nacional de Investigaciones Científicas y Técnicas de la Argentina (CONICET) y actualmente labora en el Departamento de Geografía y Turismo de la Universidad Nacional del Sur de Bahía Blanca, Argentina.

*** Doctor en Geografía por la Universidad de Málaga (Espańa). Actualmente labora en el Departamento de Geografía de la Facultad de Turismo en la Universidad de Málaga, Espańa. 


\section{Introducción}

$\mathrm{T}$

radicionalmente el turismo ha sido un fenómeno poco estudiado desde la ciencia política, por ser considerado un campo de poca profundidad (Hall, 1998. El notable crecimiento de la actividad turística desde mediados del siglo $\mathrm{xx}$, ha suscitado un evidente interés en los gobiernos nacionales e incluso en los organismos internacionales, pero este hecho no se ha traducido en un claro incremento del análisis del turismo por parte de la ciencia política (Richter, 1983; Matthews, y Richter, 1991; Fayos-Solá, 2004; Hall, 2010; Velasco, 2011; Scott, 2011).

A diferencia de otras ciencias, la política ha postergado el análisis del turismo tanto en sus aspectos teóricos como prácticos. Los primeros estudios del área se hicieron en 1970, cuando la ciencia política se interesó más por los aspectos aplicados. A partir de entonces, se observa un crecimiento de estas investigaciones, especialmente de aquellas relacionadas con el análisis del turismo como factor de desarrollo económico (Jenkins, 1980; Williams, y Shaw, 1988; Scott, 2011). No obstante, el análisis turístico siguió siendo minoritario.

Matthews, y Richter (1991) explican este desinterés de la ciencia política por el turismo debido a que esta se entiende principalmente como una simple actividad privada. Velasco (2011) señala que la escasez de análisis politológicos se funda en la primacía de la perspectiva económica. Sostiene que se ha pretendido asociar la política turística con la idea de una actividad de consumo. De esta forma se ha sacado el turismo de la esfera de lo público y se lo ha situado en el marco del sector privado.

La ciencia política es una pieza fundamental para comprender el turismo, proporciona conceptos e instrumentos metodológicos que enriquecen notablemente la compresión del fenómeno. La contribución a la balanza de pagos, la creación de empleos directos e indirectos, el fortalecimiento de las economías locales, la construcción de las imágenes nacionales, la mejora en el bienestar social y sus impactos ambientales y culturales, demandan que el hecho turístico se convierta en un área prioritaria de investigación y docencia de la ciencia política (Scott, 2011).

En este sentido, Velasco $(2002,2011)$ afirma que la perspectiva de análisis de políticas públicas constituye un vía posible para el análisis de la política turística que: "[...] permite acometer una visión integral de las acciones públicas llevadas a cabo en materia de turismo" (Velasco, 2002: 3). El enfoque incluye una variedad de análisis de contenidos en dos extremos: el estudio de un elemento específico de la política o el examen de la política en su entorno como su variable dependiente. 
El turismo presenta una naturaleza compleja, en la que se interrelacionan los factores económicos y políticos, así como los geográficos y recreacionales (Hall, 1998). De acuerdo con esta postura, la política turística se entiende en principio como un campo multidisciplinar (Kosters, 1984; Bote, y Marchena, 1996). En este contexto, las definiciones sobre política turística son variables, pero se podría destacar la aportación de Hall (2010) que entiende la política pública del turismo como lo que el gobierno hace o no hace en relación al turismo, lo que deja un amplio campo de reflexión a los investigadores del turismo.

La política turística presenta diferentes funciones, que dependen de una variedad de factores como la estructura económica y social, la estructura del sector turístico, la capacidad de intervención del Estado y la ideología imperante, entre otros. Como se analiza en los próximos apartados, el modelo de producción económico y la estructura política son factores clave en la política turística de Argentina. En este caso, la investigación pone de manifiesto el carácter multifacético que adquiere el turismo en tanto asunto público, según diferentes objetivos gubernamentales de cada periodo.

El objetivo principal del estudio es el análisis de la evolución de la política turística en Argentina teniendo en cuenta el contexto social, económico y político y la relación entre la política turística y la intervención estatal. El estudio describe las principales funciones que desempeña el turismo en las etapas evolutivas de la política turística teniendo como referencia los modelos de producción económico-turísticos: prefordista, fordista y posfordista. En este sentido, el abordaje de la política nacional se realiza teniendo en cuenta la interdependencia entre las estructuras internas y las relaciones económicas y políticas internacionales (Gourevitch, 2011).

El sector turístico está íntimamente conectado con los procesos de acumulación y producción del capitalismo. Las similitudes entre las formas de organización de la actividad productiva en la industria y el turismo es lo que lleva a que se pueda aplicar los citados procesos prefordistas, fordistas y posfordistas para su análisis (Ioannides, y Debbage, 1997; Garay, y Cánoves, 2011). El turismo es un buen testigo para comprender la evolución de la economía y la política en los últimos 130 años y en especial en las últimas décadas, ya que este ha sido uno de los grandes centros del proceso de globalización de la economía y la sociedad mundial (Go, y Pine, 1995; Hjalager, 2007).

El prefordismo está ligado a los procesos productivos artesanos, con poca tecnología, en buena parte realizados antes de la revolución industrial. En el caso del turismo, el prefordismo se manifiesta mediante la empresa familiar (el pequeño hotel familiar), la comercialización limitada y la promoción turística basada en la información turística directa. Por su parte, el fordismo se caracteriza 
por la producción en masa de bienes y servicios estandarizados, para reducir sus costos unitarios de producción. La economía de escala y la concentración industrial juegan un papel fundamental. Estos principios fueron los que dieron lugar al turismo de masas, fenómeno creado por las grandes compañías áreas, cadenas hoteleras y tour-operadores. Por último, el posfordismo, también conocido como "modelo de acumulación flexible", es un modo de producción industrial que incide en la flexibilización de la producción y de la mano de obra. El turismo posfordista propone la oferta segmentada frente al turismo de masas y utiliza ampliamente las nuevas tecnologías para expandir el turismo globalmente (Donaire, 1998). A partir de los años noventa, el turismo, en alianza con el capital financiero e inmobiliario, ha generado un gran incremento de la actividad turística a nivel global, no hay ningún espacio terrestre o marítimo que no tenga posibilidades turísticas.

Metodológicamente este estudio utiliza un enfoque institucional para el análisis de la política turística (Lash, 2011). El examen de esta política explica, por un lado, el papel del Estado en relación al propio sector turístico, la estructura político-administrativa y la utilización del turismo como factor de desarrollo; y, por otro, estudia la ideología dominante y la relación del turismo con grupos sociales. De forma más concreta, este enfoque se enmarca en el debate sugerido por diversos autores en torno a la teoría de la regulación (Lash, y Urry, 1987; Boyer, 1990; Mair, 2006). Esta propuesta investiga las formas en las que el capitalismo (como institución) se mantiene a pesar de sus contradicciones y cómo puede llegar a estabilizarse. Específicamente, aborda el cambio que se produjo al pasar del fordismo al posfordismo, incluyendo las transformaciones habidas en las estructuras estatales.

Utilizando el citado enfoque, esta investigación se plantea como reflexión y debate en torno a la política turística y a la intervención estatal. Este hecho se ha traducido en una amplia revisión de la literatura internacional y nacional sobre el tema. Y de forma concreta, el análisis se ha centrado en un estudio de caso, que es la República Argentina. Este país permite un estudio extendido en el tiempo, que presenta características singulares que hasta ahora no habían sido identificadas. Argentina es un magnífico laboratorio para observar los cambios globales en los procesos de acumulación del capitalismo, a la vez que presenta elementos particulares.

La actividad turística en Argentina es parte de las competencias concurrentes que comparten los diferentes niveles gubernamentales. La forma federal de gobierno hace que converjan en materia turística políticas, normativas, organismos, actores, planes, de los diferentes niveles de gobierno: nacional, provincial y municipal. La investigación que se desarrolla a continuación presenta como nivel competencial de análisis el gobierno nacional. La complejidad de cada 
estructura administrativa particular requiere de análisis específicos, que alcancen el nivel de profundidad necesario.

Para este análisis de caso, se han utilizado técnicas de observación y análisis de documentos en sus aspectos empíricos, empleando diversas fuentes. Esta labor ha requerido un importante trabajo de campo, con visitas a los principales organismos turísticos. Por un lado, se ha realizado una amplia revisión documental que incluye textos normativos (leyes, decretos, resoluciones, etc.), manifestaciones oficiales (discursos, informes y prensa pública), documentos de especialistas en el área (informes de la Organización Mundial del Turismo y de otros organismos estatales). Y por otro lado, se ha recopilado una gran cantidad de fuentes estadísticas:, Encuesta de Viajes y Turismo en Hogares Argentinos (Indec y MINTUR, 2008, 2011), Anuario Estadístico de la Organización Mundial del Turismo 2012 y estadísticas proporcionadas por el Ente de Promoción del Mar del Plata. Los datos recopilados son los que permiten construir los gráficos 3, 4 y 5 y, además, respaldan las afirmaciones de este estudio. El análisis del corpus de investigación permite plantear una propuesta de fases evolutivas de la política turística.

Este trabajo aporta algunas contribuciones destacables. En primer lugar, se presenta uno de los escasos análisis de la política turística desde la ciencia política en el ámbito latinoamericano. Habitualmente ha predominado la indulgente perspectiva económica del turismo que vacía la actividad de conflictos. Se plantean tres fases principales para el estudio evolutivo de la política turística de Argentina. En segundo lugar, se propone la existencia de un modelo turístico particular de carácter endógeno, construido en el tiempo en función de la intervención estatal y la estructura económica y social del país. Este modelo presenta complejas funciones que se despliegan según la estructura socioeconómica y el grado de intervención estatal (funciones territoriales, funciones sociales y funciones económicas).

\section{La evolución de la intervención estatal en la política turística}

Los notorios beneficios generados por el turismo en los años cincuenta y sesenta del pasado siglo al calor del turismo de masas, provocaron que los Estados occidentales dejaran de percibir el turismo como una actividad económica secundaria (омт, 1983). La razón fue simultánea en varios casos; la crisis de posguerra obligó a algunos países del sur de Europa a buscar divisas a corto plazo, mientras que los países del centro y norte del continente, junto a Estados Unidos, descubrieron el turismo de masas como una gran oportunidad de negocio (Almeida, 2012). El turismo se convirtió en una gran herramienta 
económica y política. Por un lado, numerosos países apostaron por el turismo como palanca de desarrollo (Williams, y Shaw, 1988) y, por otro, el bloque occidental favoreció el turismo como barrera para dificultar la difusión del comunismo (Hillali, 2007).

Los gobiernos de los países turísticos crearon departamentos destinados a la promoción exterior y la captación de inversión internacional (OMT, 1983; Lickorish, 2000). Una publicación de la Organización Mundial del Turismo (омт) de los años ochenta subrayaba las responsabilidades que el Estado debía tener respecto a la actividad turística, afirmando que "el Estado debe conceder al turismo el lugar y la prioridad que merece el conjunto de la actividad económica y social [...]" (омт, 1983: 4). De esta forma, el Estado se convirtió en un garante de la inversión foránea y también en un promotor turístico.

En los inicios del turismo moderno se produjo una clara intervención estatal en el sector, hecho que ha variado con posterioridad en función del nivel de desarrollo económico, grado de dependencia hacia el turismo, orientación ideológica de los gobiernos, etc. (Jenkins, y Henry, 1982; Britton, 1982; FayosSolá, 1996). La política que acompañó al crecimiento del turismo fordista no sufrió grandes cambios hasta finales de los ochenta y comienzo de los noventa. En estas fechas, irrumpe el posfordismo que favorece otros procesos como la flexibilización de la producción, la competitividad y la segmentación de la demanda, dentro de un proceso de amplia globalización (Fayos-Solá, 1996). Con ello, el Estado disminuye su intervención en favor de la iniciativa privada y los destinos locales y regionales (Vernon et al., 2005).

Los amplios beneficios económicos generados por el turismo ocasionaron que la discusión política no se centrara en la mayor o menor intervención de los Estados en el sector, sino en la manera de llevarla a cabo, es decir, en la gestión. En este sentido, Matthews, y Richter (1991) sostienen que la cuestión ideológica no responde a la intervención o no de los gobiernos en el sector - hasta los conservadores intervienen - sino a quiénes se beneficia con la política turística del gobierno. Esta situación ha llevado a que la planificación turística y la política turística se presenten en muchos casos como fases superpuestas. $\mathrm{Al}$ suponerse que el turismo es una actividad irrenunciable, el análisis se centra en su planificación e implantación más que en un genuino debate ideológico y político acerca de su impacto (Scott, 2011).

En este punto, es preciso resaltar que el turismo es un fenómeno construido que emerge a partir de la concepción político-económica imperante. Por tanto, no se puede analizar la intervención estatal en el área o una política turística específica sino en relación con el paradigma vigente. Es fundamental no descontextualizar el análisis. En este sentido, Hall (2011) afirma que las formas en que las políticas turísticas son diseñadas tienen implícitos fundamentos 
teóricos acerca del papel adecuado del Estado, la relación entre el Estado y los demás actores, la selección de instrumentos de política, y la definición de los problemas a resolver. Para una mejor comprensión de los procesos de política turística y sus resultados, es fundamental que lo empírico no esté divorciado de lo teórico.

El papel del gobierno en el sector vinculado en sus inicios a la ampliación social del ocio, ha presentado un cambio radical en los últimos treinta años. El proceso de globalización ha consolidado el liberalismo económico y reducido el peso del Estado, potenciando la acción privada y disminuyendo el gasto público. La evolución del Estado de bienestar hacia el neoliberal ha generado nuevas relaciones público-privadas que transforman sustancialmente la gestión turística y dan paso al proceso posfordista (Owen, 1992; Fayos-Solá, 1996; Lickorish, 2000; Higgins-Desbiolles, 2006; Hall, 2010; Arcarons, 2010; González, 2010; Scott, 2011).

Hall (2010) afirma que de un modelo tradicional de la administración pública que desarrolla la política turística en relación al bien público, se ha pasado a un modelo corporativista que hace hincapié en la eficacia, el rendimiento de las inversiones, el papel del mercado y la relación entre los actores involucrados. Las organizaciones turísticas nacionales y regionales reducen sus funciones de desarrollo, planificación y políticas, en favor de la comercialización y promoción. Se abandona la centralización estatal para permitir una mayor participación de las asociaciones profesionales, lo mismo que de las redes y relaciones de colaboración entre los actores involucrados. El turismo como "fuerza social" del Estado interventor da paso al turismo como "industria" de la gestión, que estructura la actividad con base en criterios económicos (Higgins-Desbiolles, 2006).

En este sentido, Hall (2010) afirma que el nuevo papel del Estado genera un dilema político: "Por un lado se demanda menos interferencia del gobierno en el mercado, mientras que por otro lado, los grupos turísticos y afines buscan que el gobierno desarrolle políticas que favorezcan a estos grupos económicos, incluyendo el mantenimiento de los fondos gubernamentales para la promoción y el desarrollo" (Hall, 2010: 10). Fayos-Solá (2004) afirma la existencia de una "nueva política turística" en la era de la globalización, que busca principalmente el posicionamiento de los destinos turísticos y la calidad y eficacia turística. Destaca el papel decisivo de las administraciones locales, regionales y supranacionales en detrimento de las competencias de las administraciones nacionales.

Este cambio de paradigma no solo transforma la política turística de los gobiernos, sino también el análisis académico del fenómeno. En este sentido, es interesante observar el recorrido que ha tenido el papel del Estado y la política 
turística: en menos de veinte años se ha pasado de exaltar el papel que debe jugar el Estado, tal y como recomendaba la OMT en sus informes de los años ochenta, a dar por finalizada la intervención estatal en el área. A fines del siglo xx, de acuerdo a la filosofía neoliberal, la OMT afirma que la política turística debe limitarse a garantizar las condiciones de competencia en el mercado turístico cuando no la haya, a ofrecer ciertos bienes no rentables para el sector privado o establecer impuestos, subvenciones y regulaciones. El Estado asume la iniciativa pública siempre y cuando el mercado se manifieste incapaz (oMT, 1998). En esta misma línea, Arcarons (2010) señala que el gran reto de la política turística actual es compatibilizar el principio de libertad de mercado con la preservación de los recursos que aseguren la continuidad de la actividad turística. Es resumen, se establece un nuevo enfoque de la política turística, esencialmente económico, que justifica la intervención pública solo en aquellos casos donde el mercado presente fallas.

\section{Evolución de la política turística argentina}

Son diversas las investigaciones que han analizado la evolución del turismo en Argentina (Schlüter, 2003; Capanegra, 2006, 2011; Wallingre, 2007a; Lara, 2008; Pastoriza, 2011), desde los incipientes viajes aristocráticos del siglo XIX a la consolidación del turismo como política de Estado dos siglos después. El análisis de este recorrido permite estudiar las diferentes funciones que atraviesa el turismo como política pública a lo largo de la historia argentina contemporánea. En este sentido, se destacan las fases propuestas por Capanegra (2006) y Lara (2008). El primer autor propone una serie de etapas en la evolución de la política turística en función del modelo de desarrollo económico nacional que coincide con grandes ideas o valores sociales de cada momento: agroexportador, como instrumento de civilización y progreso; de sustitución de importaciones, como instrumento de cooptación social y planificación, y aperturista, como instrumento de internacionalización económica. El segundo autor establece una serie de etapas que se identifica con algún elemento destacado en la política turística de Argentina: prehistoria, bases del turismo nacional, institucionalización, turismo social, turismo de aventura y política de Estado.

Teniendo en cuenta las fuentes documentales y estadísticas analizadas y las aportaciones de diversos autores sobre la producción turística (Fayos-Solá, 1996; Donaire et al., 1997; Capanegra, 2006; Lara, 2008; Garay, y Cánoves, 2011; Enríquez et. al, 2012), se proponen tres grandes fases en la política turística en Argentina: i) (1880-1930) la prefordista o artesanal, en la que 
la actividad turística es una actividad minoritaria destinada a una élite; ii) (1930-1975) la fordista o industrial que se identifica con el turismo de masas en el que el turismo se convierte en un derecho social debido a una fuerte intervención estatal y, finalmente, iii) (1975-2011) la transición al posfordismo o de internacionalización, que desarrolla un turismo diferenciado, flexible y competitivo, dentro de un proceso de retracción de la intervención del Estado, pérdida de derechos sociales y aumento de la iniciativa privada (gráfico 1).

El análisis destaca la importancia que adquiere el turismo como política pública a lo largo de la historia reciente de Argentina. Aquello que se inicia como una práctica privada, exclusiva de círculos de élite, fue adquiriendo "significancia pública" con su progresiva masificación. Así pues, se pasa de una destacada intervención estatal en el sector a mediados de siglo $\mathrm{xx}$, a una clara primacía privada en los últimos decenios de dicho siglo, en los que irrumpe la corriente neoliberal.

Gráfico 1. Evolución de la política turística en la Argentina

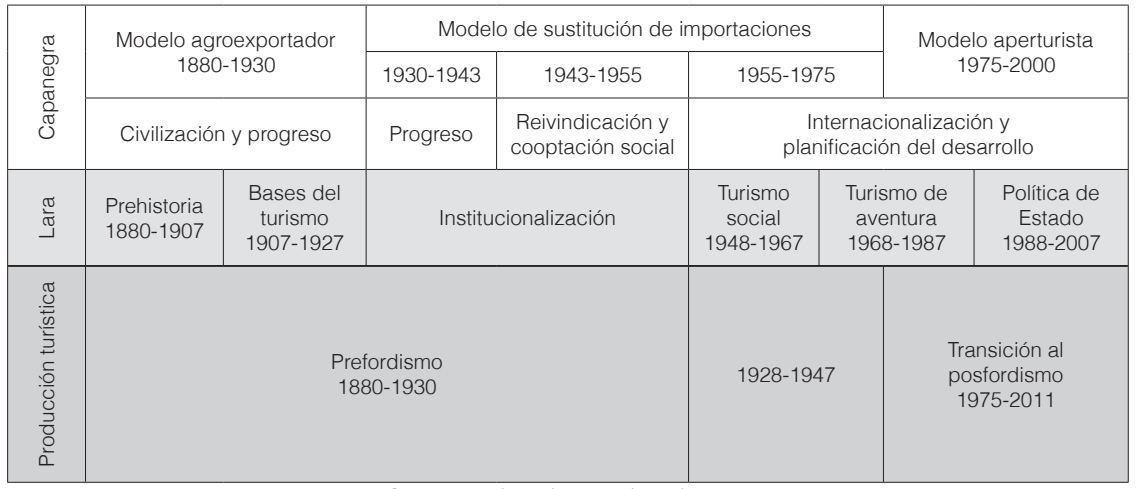

Fuente: Elaboración propia con base en Capanegra (2006) y Lara (2008).

Asimismo, el análisis señala la condición multifacética del turismo, que admite su abordaje desde diversos enfoques públicos en función de las preferencias gubernamentales (Velasco, 2002). Este trabajo pone a la vista una serie de funciones predominantes en la política turística en la Argentina que se identifican en cada una de las fases: i) funciones territoriales, relacionadas con la consolidación de la soberanía nacional y la urbanización en la fase prefordista; ii) funciones sociales, vinculadas a la reivindicación social en la fase fordista; iii) funciones económicas, centradas en torno al turismo como factor de desarrollo y de internacionalización económica, en la fase de transición al posfordismo (gráfico 2). 


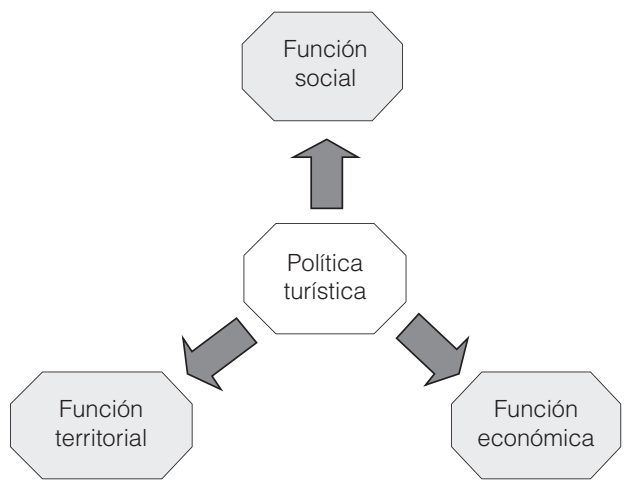

Fuente: Elaboración propia.

\section{La etapa prefordista: los orígenes del turismo en Argentina}

A fines del siglo XIX, Argentina se incorpora al mercado mundial como exportador de materias primas agropecuarias e importador de manufacturas de los países centrales. Acontece en el país un proceso modernizador sustentado en la extensión del ferrocarril y la llegada de inmigrantes (Torrado, 2010). Este proceso consolida a una aristocracia terrateniente de estilo europeo, que realiza los primeros viajes con fines recreativos: las largas estadías en Europa, se intercalan con el veraneo en segundas residencias a orillas del Río de La Plata y la práctica de baños termales.

La llegada de los ramales ferroviarios además de generar accesibilidad, impulsa la construcción de los primeros hoteles de lujo, al estilo belle époque. En este marco nace Mar del Plata y posteriormente otro conjunto de destinos atlánticos, como enclaves de élite (Schlüter, 2003). Mar del Plata imitaba las clásicas ciudades balnearias del Atlántico francés e inglés de fines del siglo XIx y servía como centro de ocio para la élite dirigente de Buenos Aires (Mantobani, 1997). En este periodo, el turismo, socialmente, es una actividad restringida que tiene un impacto limitado desde el punto de vista económico; es el modelo prefordista (gráfico 3). El sector turístico se estructura con base en hoteles familiares de los sectores aristocráticos y de las empresas ferroviarias de capital inglés, y va delineando una producción fundamentalmente artesanal.

La escasa intervención estatal en el sector durante este periodo es suplida por la destacada actividad de las asociaciones privadas como el Touring Club Argentino (TCA) y el Automóvil Club Argentino (ACA) que tuvieron un papel decisivo en la difusión del turismo a través del automóvil (Piglia, 2008). Este 
vehículo también jugó un papel territorial importante al permitir la consolidación de numerosos enclaves balnearios en la costa próxima de Buenos Aires y la difusión de las segundas residencias. Y por otro lado, en estas fechas el turismo se unió a la política de protección ambiental mediante la aprobación del primer parque nacional: el Parque Nacional del Sud. De esta forma se creó el primer órgano público con competencias en el área turística, la Comisión Pro Parque Nacional del Sud.

Gráfico 3. Evolución de los turistas alojados en establecimientos turísticos de Mar del Plata. Fases de la política turística argentina

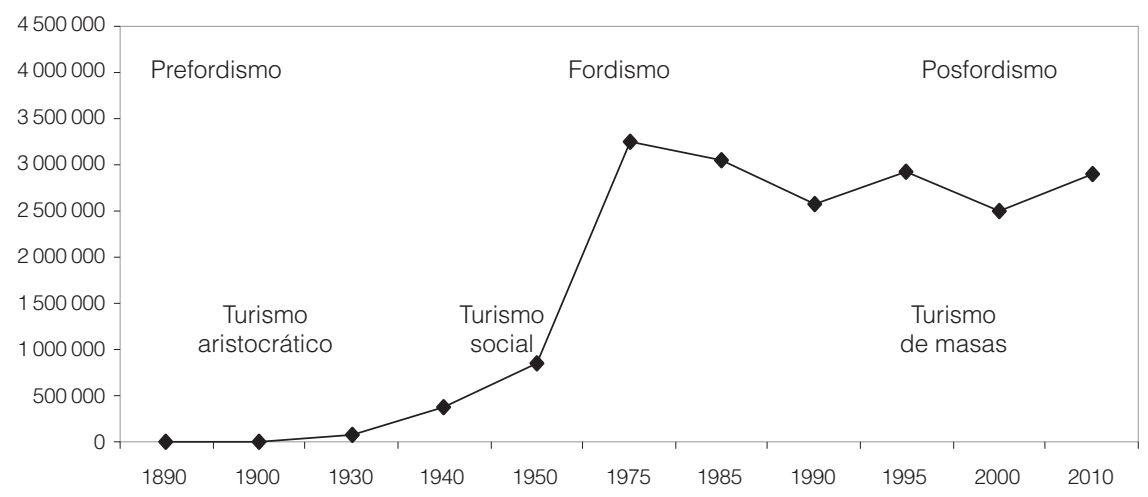

Fuente: Elaboración propia a partir de datos aportados por el Ente Municipal de Turismo de Mar del Plata (EMTUR) y Pastoriza (2008).

El impulso a estas áreas naturales se lleva a cabo junto con la localización de grupos poblacionales con el objetivo de consolidar la soberanía nacional en los extensos territorios despoblados. En esta primera etapa, el turismo desempeña una función territorial, que se relaciona con la necesidad de consolidar un Estado nacional en incipiente desarrollo. En palabras de Capanegra (2006), el turismo actúa como un "instrumento de progreso", que refleja el paso de un país rural a uno urbano. Es un turismo incipiente, minoritario y selecto que refleja un país que avanza hacia la "modernidad".

\section{La etapa fordista. Un turismo ampliado y social}

Entre 1930 y1975 se impone un nuevo modelo de acumulación que sustenta la base para la creación de un Estado de bienestar. A partir de la crisis 
internacional de 1929, el modelo agroexportador es reemplazado por otro de corte industrial basado en la sustitución de importaciones (Torrado, 2010; Ferrer, 2010; Rapoport, 2010). Se implanta un proceso de producción fordista, que fabrica bienes baratos enfocados al mercado nacional y da empleo a un gran número de trabajadores. En este marco, se desarrolla un proceso de promoción social, que conforma la estructura social moderna de Argentina. Es la etapa del "[...] paso de un modelo de ocio aristocrático a otro democrático" (Pastoriza, 2011: 256). En este contexto se produce el ascenso social de las clases medias y sectores populares, que origina la democratización de bienes y servicios antes exclusivos de la "oligarquía", entre los que se incluyen las prácticas turísticas. Estos nuevos viajeros utilizan una oferta estandarizada de precios bajos, que está impulsada en muchos casos por el propio Estado. Los destinos ofertados preferentemente se encuentran en la costa atlántica de la provincia de Buenos Aires y en la provincia de Córdoba. Este nuevo turismo de sol y playa presenta una oferta muy concentrada en algunos balnearios y se caracteriza por largas estadías, una fuerte estacionalidad estival y la utilización del ferrocarril como medio de transporte (Schlüter, 2003).

Por otro lado, la protección de la naturaleza y su disfrute toman una mayor importancia en la primera etapa de este periodo. En este apartado hay que destacar la labor de Ezequiel Bustillo en la promoción de los espacios naturales. Gracias a su trabajo se crean nuevos parques nacionales y se aprueba la primera Ley Nacional de Parques (núm. 12.103), que establece la Dirección de Parques Nacionales, donde se ubica la primera oficina de turismo de Argentina. Desde el primer momento se ligó la labor de protección con el uso turístico, de ahí que se levantara hoteles en los entornos de los espacios naturales, siguiendo la línea de lo realizado en Estados Unidos, destacando el afamado hotel Llao Llao en Bariloche (Schlüter, 2003; Capanegra, 2006; Pastoriza, 2011). Por otro lado, se amplía la red de carreteras, se implanta una política de equipamiento urbano para el desarrollo turístico y se funda la primera Línea Aérea del Estado (LADE). La mejora de los transportes y la red de espacios naturales son elementos que ponen de relieve la función territorial del turismo en estas fechas.

En este periodo se produce la institucionalización de la estructura administrativa del turismo de Argentina (Capanegra, 2006). La progresiva masificación de las prácticas de ocio ocasiona que el turismo vaya adquiriendo significancia pública, especialmente a partir de la década de 1940. En los años cuarenta se pone en marcha una serie de medidas que da forma a la estructura turística de Argentina. En 1941, el gobierno crea la Comisión Nacional de Turismo, bajo la órbita del Ministerio de Agricultura, para poco después otorgarle el rango de dirección. 
En el ámbito político, la llegada de Juan Domingo Perón al poder en $1943^{1}$ provoca un cambio abrupto en el turismo de Argentina. El gobierno eleva de categoría el turismo y lo trata como una política pública específica. Uno de los elementos más destacados recogidos en la agenda política gubernamental es la consideración del turismo como un derecho del obrero. En este sentido, el Estado asume funciones de promotor, con la finalidad de estimular el turismo a través de los nuevos viajeros beneficiados por el derecho a las vacaciones pagadas. El derecho a las vacaciones pagadas se inició en Francia en 1936 y se fue extendiendo a los países occidentales europeos a lo largo de los ańos treinta y cuarenta (Pastoriza, y Pedetta, 2009). En Argentina se aprobó en 1945 a partir del decreto $\mathrm{N}^{\circ} 1740$, que extendía el derecho a todos los trabajadores y empleados argentinos en relación de dependencia.

En la etapa peronista la actuación estatal en el campo turístico es amplia y alcanza la construcción de sus propios complejos vacacionales (Chapadmalal y Embalse) o el impulso a los hoteles sindicales (Pastoriza, 2011). Así mismo, se reestructura la histórica Dirección de Parques Nacionales que pasa a denominarse Administración de Parques Nacionales y Turismo. El nuevo organismo incluye competencias relacionadas con el turismo, y los hoteles bajo su jurisdicción se incorporan a las listas de hospedajes estatales. Schlüter afirma que "[...] la política que implantó la Dirección de Parques Nacionales durante el periodo 1944/1955 se caracterizó por atender las necesidades de los sectores sociales de menores recursos" (Schlüter, 2003: 70). En este sentido, la autora sostiene que la llegada del peronismo al poder cambió el rumbo del país y también el enfoque del fenómeno turístico. En esta fase, el turismo adquiere por primera vez a nivel nacional una destacada función social. Esta situación se comprueba en el fuerte crecimiento turístico del principal destino nacional que es Mar del Plata entre los ańos 1940 y 1955 (gráfico 3). Este destino refleja en buena parte la evolución de la demanda turística interna de Argentina.

El gobierno peronista promueve un modelo inclusivo, basado en un proceso de redistribución de la renta nacional, en el cual el turismo forma parte de los bienes que se pretende "democratizar". Por lo tanto, en coordinación con los sindicatos y la Fundación Eva Perón, se implanta una ambiciosa política de turismo social, tendente a garantizar el acceso al turismo y al ocio a sectores sociales de bajos ingresos. La medida implicó enfrentarse a la élite

1 Perón participa en el golpe militar de 1943 comandado por el Grupo de Oficiales Unidos (GOU), que pone fin al gobierno conservador de Ramón Castillo. Luego de desempeñar diferentes cargos en el nuevo gobierno, Perón fuerza la convocatoria de elecciones democráticas, que lo llevarán a la presidencia en 1946. Este cargo lo mantendrá hasta su derrocamiento en 1955, con un nuevo golpe de Estado a manos de la Revolución Libertadora. 
conservadora, que debió trasladarse a nuevas áreas vacacionales ante la irrupción de los nuevos turistas. Un efecto colateral de esta medida política fue la potenciación del balneario de Punta del Este (Uruguay) que acogió a las clases acomodadas que huían de la popularización de Mar del Plata y otros destinos (Campodónico, y Da Cunha, 2009). A partir de entonces, el destino para la alta burguesía argentina se va a encontrar en Uruguay, con lo que efectos socioeconómicos y territoriales de la política turística traspasan el propio país, siguiendo la pauta de expansión de los países desarrollados y el propio modelo turístico de difusión de Gormsen ${ }^{2}$ (1981). Esto es un hecho singular en Latinoamérica.

El gobierno de Perón impulsó otras actuaciones destinadas a consolidar una estructura turística nacional: nacionalización de los ferrocarriles (1946-1948), creación de Aerolíneas Argentina (1950) y la constitución de la Asociación Argentina de Agentes de Viajes, Turismo y Afines (АAAVyт) (1951). Hay que senalar que las políticas impulsadas consolidan un proceso de ampliación social del ocio, que se había iniciado en los años treinta con el avance de las clases medias (gráfico 3). Scatzanella (1998) y Capanegra (2006) sostienen que, en esta etapa, el turismo, además de representar la ampliación social de las prácticas vacacionales, cumplía una importante función simbólica que promovía la cooptación de seguidores para el sostenimiento del "régimen".

Con el golpe de Estado de 1955, se inicia el extenso periodo de proscripción del peronismo (1955-1973), en el que se alternan gobiernos dictatoriales y "democracias restringidas". ${ }^{3}$ Los nuevos gobiernos ponen en marcha un modelo económico desarrollista, a la vez que se dan los primeros pasos para la planificación en el sector: la Dirección Nacional de Turismo pasa a ser un ente autónomo (1957) y se impulsa la primera Ley Nacional de Turismo (la Ley 14.574/58), que sienta las bases para los primeros planes de desarrollo turístico. Paralelamente a estas primeras aproximaciones a la visión económica del turismo, que inicia el desarrollismo, continúa el proceso de ampliación social del ocio que identifica al periodo, impulsado por la estructura social ascendente que caracterizó al país hasta mediados de los setenta (gráfico 3).

Con los posteriores gobiernos militares, se crea la Secretaría de Turismo, que tiene una misión fundamentalmente propagandística. Finalmente, con el breve regreso del peronismo al gobierno en 1973, resurge el enfoque social y político del turismo: se crea el Ministerio de Bienestar Social, con una Secreta-

2 Este modelo espacio-temporal explica la evolución histórica de los espacios turísticos mediante una creación sucesiva de destinos turísticos que terminan creando periferias turísticas mundiales.

3 El término de "democracias restringidas" responde a la tutela de las fuerzas armadas de los gobiernos electos y a la proscripción del partido de adhesión mayoritaria, el peronismo. 
ría de Estado de Deportes y Turismo y las subsecretarías de deportes, turismo y turismo social, que tendrán su fin con el último golpe militar.

\section{Transición al posfordismo. La internacionalización del turismo}

En este periodo se producen numerosos cambios políticos, sociales y económicos que afectan a la política y al sector turístico. Por un lado, la estructura económica nacional comienza a vislumbrar ciertas limitaciones que se traducen en repetidas crisis económicas, inflación, crecimiento de la deuda pública, pérdida de poder adquisitivo de la población, etc. Por otro, esta situación coincide con un cambio en los modelos productivos mundiales, posteriores a la crisis del petróleo de 1973. Los avances tecnológicos y la globalización económica, facilitan una producción de tipo posfordista, que promueve estructuras flexibles y complejas a escala global, dentro de un proceso de creciente competencia mundial y deslocalización industrial.

Esta transformación se hará más evidente a mediados de los años noventa, cuando se produzca un importante proceso de liberalización de la economía y la privatización de los servicios públicos de Argentina; hecho coincidente con el fuerte proceso de globalización económica. En este marco, se producen notables cambios sociales en los últimos decenios. La base social del modelo fordista consolidado en los años cuarenta se desintegra, el modelo de acumulación y producción aperturista socava las estructuras laborales formales, aumentando la pobreza y precarizando los derechos sociales, incluyendo aquellos ligados a la recreación y al turismo.

En el marco de la crisis del petróleo, el golpe de Estado de 1976 favorece un modelo de producción de claro corte liberal, profundizado por los sucesivos gobiernos democráticos, que pondrá fin al Estado de bienestar argentino. La economía sufre fuertes oscilaciones que repercuten negativamente en la estructura productiva. A partir del fácil acceso al crédito internacional y de beneficios arancelarios otorgados a las importaciones, se desmantela el tejido industrial y se impulsa una economía de servicios. Luego de la crisis hiperinflacionaria que atravesó el país hasta entrada la década de los noventa, se impulsa una serie de cambios estructurales, que refleja la inserción definitiva de Argentina en el modelo neoliberal; entre dichos cambios se incluye un amplio programa de privatizaciones y la desregulación de sectores claves de la economía (Ferrer, 2010; Rapoport, 2010).

En este nuevo contexto, el turismo internacional adquiere significancia pública como foco de atracción de las necesarias divisas internacionales. El sector turístico se conforma como factor de crecimiento económico, predominando 
claramente su función económica. El turismo y el ocio como derecho social se convierten en un aspecto absolutamente secundario. Así pues, se decide poner en marcha actuaciones similares a las realizadas en otros países turísticos. La nueva orientación de la política turística encuentra el referente necesario en las recomendaciones de los organismos internacionales. El Fondo Monetario Internacional (FMI), el Banco Mundial (BM), el Banco Interamericano de Desarrollo (BID), la Organización de Estados Americanos (OEA) y la Organización Mundial de Turismo (омт) aconsejan a los gobiernos una mayor liberalización del sector y una menor intervención estatal.

A fines de siglo $\mathrm{xx}$, muchos países apuestan por el turismo como una clara herramienta para consecución del desarrollo económico, mediante un sector poco intensivo en tecnología, que, a decir de muchos autores, tiene un impacto económico muy positivo: creación de empleo, mejora de la balanza de pagos, efecto multiplicador sobre otros sectores, generación de renta fiscal, incremento de la renta de las capas más desfavorecidas, etc. (Williams, y Shaw, 1988; Monfort, 2000; Magadán, y Rivas, 2012). En cambio, poco se comenta de los problemas económicos, sociales y ambientales que genera y de la dependencia externa que en muchos casos puede producir (De Kadt, 1979; Britton, 1982; Pearce, 1991). Este modelo de desarrollo económico basado en el turismo es bien conocido en otros países que apostaron en los años sesenta por el turismo, como España, Italia o Portugal (Almeida, 2012).

Se comprueba la necesidad de planificar el sector turístico para dinamizarlo y captar turismo internacional, por ello se realizan varios planes de marketing estratégico y se aprueba en 1984 el primer documento de planificación pública del turismo de enfoque regional: "Bases para un Plan Federal de Turismo". Además se activa el sector privado a través de mesas de concertación (Reuniones Nacionales de Turismo). Surge la Asociación de Hoteles de la República Argentina (Ант) (1977) y la Cámara Argentina de Tiempos Compartidos (СаTC) (1984). La planificación territorial fue dando paso a la planificación por productos turísticos durante la década de los noventa y finalizó con el Plan Federal Estratégico de Turismo Sostenible de 2005, que combina las regiones turísticas con los productos consolidados (Wallingre, 2007b).

La demanda de turismo internacional crece significativamente en los últimos decenios. Prácticamente se ha cuadriplicado entre 1985 y 2011, acorde a la expansión de la actividad turística en Argentina (gráfico 4). Por el contrario, la demanda interna muestra un cierto estancamiento debido al proceso de pauperización de las clases medias, hasta la reactivación económica iniciada en 2002 (gráfico 3). Por otro lado, los flujos de turismo emisivo y receptivo sufren oscilaciones debido a los recurrentes procesos de sobrevaluación o devaluación del peso (gráficos 4 y 5). 


\section{Gráfico 4. Balanza turística de Argentina}

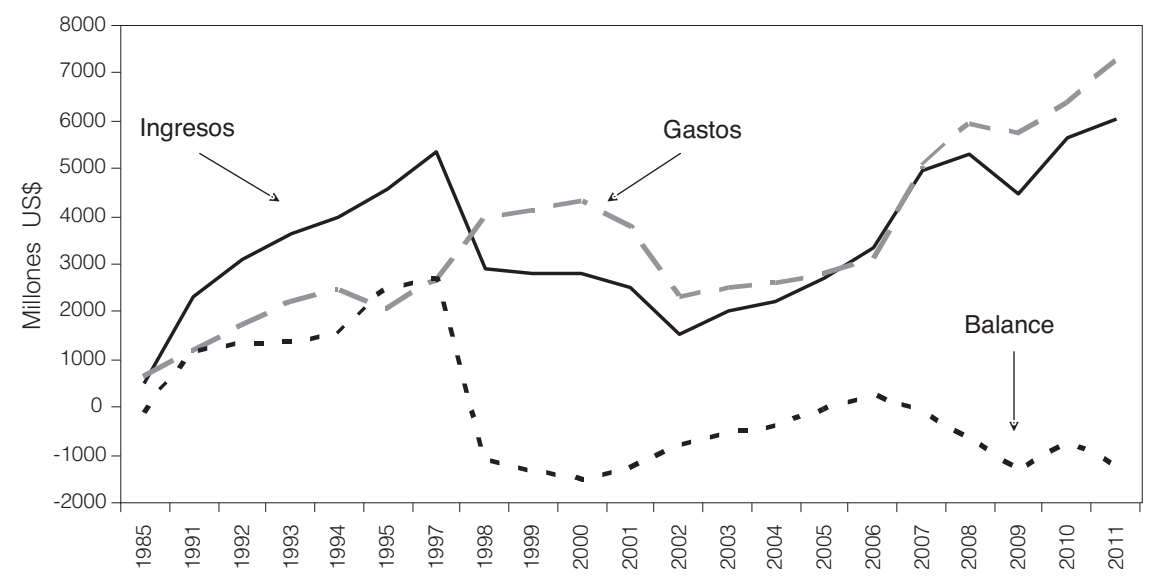

Fuente: Elaboración propia con base en datos de la OMT (2013).

Gráfico 5. Evolución del turismo internacional en Argentina

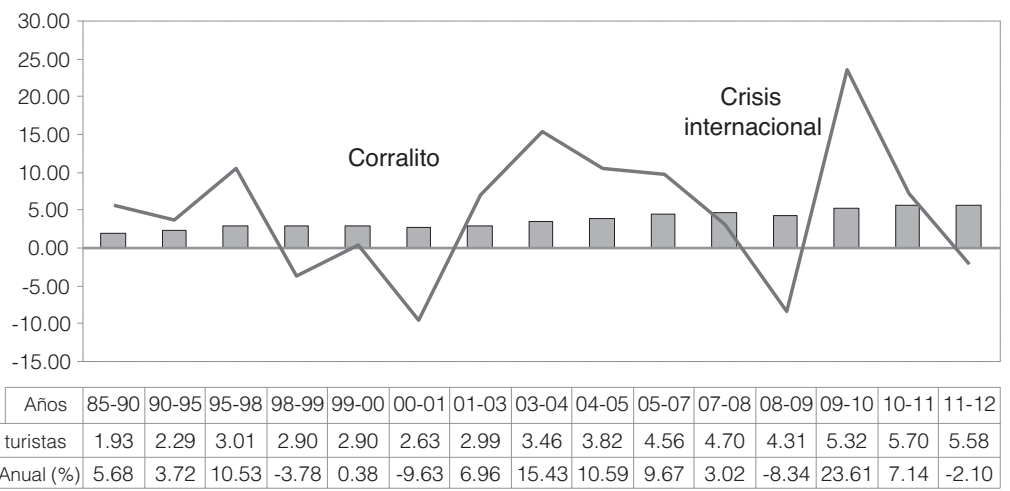

Fuente: Elaboración propia con base en datos de la OMT (2013).

Históricamente, el turismo emisivo ha superado al receptivo, con escasas excepciones. La balanza turística ha tenido tradicionalmente saldo negativo. Los datos de la OMT muestran un periodo positivo para los primeros años de la década de los noventa, pero esta situación es más explicable por un efecto contable que por un real incremento de los ingresos turísticos, sobre todo, si tenemos en cuenta que el número de turistas no experimentó un gran incremento (gráficos 4 y 5). La Ley de Convertibilidad (1991) en la que se igualó el peso argentino al dólar estadounidense favoreció la salida de turistas argentinos a lo largo de la 
década de 1990, situación que cambia marcadamente con la devaluación de 2002, que termina con diez años de paridad cambiaria.

En esta fase también se originan cambios territoriales llamativos. Desde la vertiente del turismo nacional, se produce una fuerte difusión de la segunda residencia turística en el tramo de la costa atlántica bonaerense, se crean nuevos enclaves nacionales para la élite, como Cariló y Mar de las Pampas, intentando competir con Punta del Este, y se consolida el gran destino popular de Mar del Plata (gráfico 3). A su vez, se desarrollan nuevos productos turísticos alternativos al tradicional sol y playa, como el esquí, la fauna marina, la gastronomía y trenes turísticos (Schlüter, 2003). En cuanto al turismo receptivo, surgen y se consolidan destinos para la atracción del turismo internacional, apoyándose en los recursos naturales (cataratas de Iguazú, glaciar Perito Moreno, península Valdez, Bariloche, Las Leñas) y, secundariamente, en la cultura y el paisaje (Quebrada de Humahuaca) (Bertoncello, 2008) y Buenos Aires, como ciudad de ocio y cultura (Correa, 2010).

Respecto a la estructura administrativa, se observan notables cambios en el área. A finales de los años ochenta, el área de turismo pasa de la órbita del Ministerio de Economía, a la Secretaría de Comercio Exterior, para luego retornar a la antigua Secretaría de Turismo, dependiente de la Presidencia de la Nación; organismo que será reemplazado temporalmente en los años noventa por el Ente Nacional de Turismo (ENTUR), que considera la participación privada. En el inicio del siglo XxI, esa secretaría pasa nuevamente al ámbito de la administración de Parques Nacionales y, por primera vez, el área adquiere el rango ministerial con la creación del Ministerio de Turismo, Cultura y Deportes, hasta el ańo 2002, que vuelve a ser secretaría (sECTUR, 2012).

La fuerte crisis que atraviesa el país en 2001, se convierte paradójicamente en una oportunidad para el sector. En el marco de los procesos de internacionalización y de planificación que sostienen la política turística desde la década de 1970, el turismo pasa a ocupar un lugar central en la agenda pública, tendente a atraer las necesarias divisas internacionales, ante la deficitaria balanza de pagos y la abultada deuda externa declarada en default (gráficos 4 y 5).

El Estado, por primera vez en este periodo, se reposiciona como actor clave en la planificación, coordinación y acción en materia turística. El turismo pasa a formar parte de las exclusivas doce políticas de Estado que define el gobierno nacional, dirigidas a impulsar la actividad económica, el superávit, la recaudación, la inversión pública, la infraestructura pública y el crecimiento económico (Presidencia de la Nación, 2003; Jefatura de Gabinete de Ministros, 2006).

La marcada devaluación del peso en 2002, junto a las intensas acciones en el área que promueve la Administración Nacional, impulsa una transformación de los patrones turísticos tradicionales, a partir de un destacado aumento del 
turismo internacional e interno. La sanción de la nueva Ley Nacional del Turismo ( $\left.\mathrm{N}^{\circ} .25 .997 / 05\right)$ y su Decreto Reglamentario (Decreto 1297/06), constituyen los hechos institucionales de mayor relevancia en cuarenta años, que reemplazan la antigua Ley 14.574 de 1958. Capanegra (2011) sostiene que el proceso de institucionalización del turismo como estrategia de política económica y factor de desarrollo se inicia con la aprobación de la Ley 14.574 en 1958 y se consolida con la Ley 25.997 en 2005.

En este marco se consolidan las relaciones público-privadas, se intensifica la inversión en el sector y se incrementa la participación del país en las ferias de promoción internacionales. En cuanto al órgano de turismo, la secretaría crece en autoridad y competencias: en primera instancia pasa al Ministerio de Producción, luego al Ministerio de Producción y Turismo y, finalmente, se convierte en Ministerio de Turismo (2010), órgano que se mantiene en la actualidad.

En este periodo de posconvertibilidad, Argentina alcanza el primer puesto en llegadas internacionales de América del Sur (2010-2011) (омт), Buenos Aires se impone de manera sostenida como la principal ciudad organizadora de congresos de América (ICCA), con lo que el el turismo pasa a contribuir con más del 7\% del pBi y el 10\% del empleo (MINTUR, 2012).

\section{Reflexiones finales}

Los argumentos desarrollados en la investigación ponen de relieve la complejidad que requiere el estudio de la política turística argentina. En contraste con los enfoques economicistas, que analizan el fenómeno del optimismo que emerge de la concepción del turismo como "industria sin chimeneas", se propone un análisis político que deja en claro los conflictos e intereses que toda política pública encierra. En este sentido, se destaca que el turismo es un fenómeno construido que emerge a partir de la concepción político-económica imperante. Por lo tanto, las políticas turísticas diseñadas llevan consigo las ideas y valores del gobierno y las relaciones de este con los demás actores políticos y económicos.

Desde esta perspectiva, la evolución de la política turística argentina responde a un contexto social, económico y político particular, estructurado con base en cánones internacionales vigentes. El recorrido por las diferentes etapas por las que atraviesa la política argentina, clarifica las diversas funciones que cumple el turismo como asunto público. Se manifiesta una primera función territorial, impulsada por una élite conservadora que pretende consolidar un Estado nacional incipiente. Este proceso da lugar a la creación de los primeros parques nacionales y enclaves vacacionales, al estilo de los clásicos balnearios europeos, y será Argentina uno de los primeros países sudamericanos en desarrollar centros turísticos. La década 
de 1940 pone de relieve la función social de la política turística. Este hecho sitúa a los sectores proletarios como actores clave en la conquista de las vacaciones anuales pagadas y consolida la democratización de los antiguos balnearios de élite. La llegada del peronismo al gobierno no solo implica el fortalecimiento del turismo como asunto público, en tanto derecho social, sino la irrupción de nuevos actores sociales en la gestión del turismo: los sindicatos. Finalmente, con la preponderancia de los agentes económicos nacionales e internacionales, a fines del siglo xx, la política turística adquiere una función netamente económica, convirtiéndose el turismo en un factor de crecimiento económico.

El estudio de la política turística de Argentina revela la existencia de un modelo turístico endógeno. Este se ha ido construyendo en el tiempo en función de la intervención estatal y la estructura económica y social del país. Con este modelo se hace referencia al mayor peso del turismo nacional frente al internacional, al notable gasto turístico (balanza turística deficitaria), a la intervención en la creación de destinos en otros países y a la precocidad en el inicio del fenómeno turístico. Estas características se pueden encontrar en los países desarrollados con sector turístico importante. Tal patrón se contrapone al exógeno, habitual en los países turísticos que han basado su desarrollo económico en el turismo internacional, como numerosos países del Caribe, del Mediterráneo o del Pacífico. Los fuertes cambios sociales, económicos y políticos que ha sufrido Argentina en el último cuarto del siglo XX no han permitido el asentamiento definitivo del modelo.

Dicho modelo singular de aspecto endógeno presenta una serie de características únicas en función de los factores que conforman la política turística argentina. i) Desde el punto de vista territorial, el turismo ha ayudado a la articulación del país. El turismo ha guardado una estrecha relación con los espacios naturales que se ha mantenido en el tiempo, de tal forma que en la actualidad los espacios turísticos más reconocidos a nivel internacional son los naturales: cataratas de Iguazú, glaciar Perito Moreno, península Valdez, Andes, etc. Asimismo, el turismo ha dado lugar a la construcción de una extensa conurbación turísticoresidencial en la costa de la Provincia de Buenos Aires, además de los destinos impulsados en la orilla norte del Río de la Plata (Colonia, Punta del Este, etc.). ii) Desde el punto de vista social, el modelo argentino mostró una gran originalidad al considerar el turismo como un derecho social. Esto explica en buena parte el fuerte crecimiento del turismo de masas nacional y con ello, los destinos nacionales. Esta estructura se fue desmontando en las décadas posteriores, conforme a otros postulados económicos y políticos, manteniéndose los establecimientos gestionados por los sindicatos. En pocos países del ámbito occidental se llegó tan lejos en el proceso de democratización del turismo. iii) Por último, el aspecto económico es lo que más identidad proporciona al modelo turístico de Argentina. El desarrollo económico de fines del siglo xIx y mediados del xx 
dio lugar a un desarrollo temprano de destinos turísticos, así como a un notable flujo turístico emisor, tanto a países próximos como hacia Europa. La tendencia a la salida junto con la tradicional fortaleza del peso argentino y las fluctuaciones cambiarias son las que justifican la balanza turística negativa (este hecho es común en países desarrollados como Alemania o Japón). El fuerte peso de la demanda interna queda explicado por las tempranas iniciativas del turismo social, que ampliaron el derecho de las mayorías a las vacaciones y, también, por la situación aislada respecto a los grandes países turísticos emisores. Los graves problemas económicos por los que atravesó Argentina a partir de los años setenta han ido cambiado esta estructura endógena. Este hecho ha sido coincidente con el proceso liberalizador de la economía del país y en el apartado turístico ha supuesto el abandono de un patrón turístico y económico más independiente por otro, que genera más dependencia externa.

\section{Referencias}

Arcarons Simon, Ramón, 2010, "Planificación turística de la Administración", en Oriol Izard Miralbell (coord.), Gestión pública del turismo, España, uoc.

Bertoncello, Rodolfo, 2008, Turismo y geografia: Lugares y patrimonio natural-cultural de la Argentina, Buenos Aires, Fundación Centro Integral Comunicación, Cultura y Sociedad, ciccus.

Bote Gómez, Venancio, y Manuel Marchena Gómez, 1996, "Política turística”, en Andrés Pedreño Muñoz, y Vicente Monfort Mir (eds.), Introducción a la economía del turismo en España, Madrid, Civitas.

Boyer, Robert, 1990, The Regulation School: A critical introduction, New Cork, Columbia University Press.

Britton, Stephen, 1982, "The Political Economy of Tourism in the Third World", Annals of Tourism Research, vol. 9, núm. 3.

Campodónico, Rossana, y Nelly da Cunha, 2009, "Mar del Plata y Punta del Este: Entre la permanencia y la renovación”, Estudios y Perspectivas, vol. 15, núm. 5.

Capanegra, César, 2011, "La construcción social del turismo como factor de desarrollo, Argentina 1958-2005”, Argentina, CONDET, XI Jornadas Internacionales y v Simposio Internacional de Investigación-Acción en Turismo.

Capanegra, César Alejandro, 2006, "La política turística en la Argentina en el siglo xx", Aportes y Transferencias, año, 10, vol. 1 . 
Correa, Ana, 2010, Ciudades, turismo y cultura. Nuevas perspectivas para el desarrollo equitativo de las ciudades, Buenos Aires, La Crujía.

De Kadt, Emanuel (ed.), 1979, Tourism: Passport to Development? Perspectives on the Social and Cultural Effects of Tourism in Developing Countries, Nueva York, Oxford University Press.

Donaire Benito, José Antonio, 1998, "La reconstrucción de los espacios turísticos. La geografía del turismo después del fordismo", Sociedade e Territorio, núm. 28.

Donaire Benito, José Antonio, Rosa María Fraguell i Sansbelló, y Lluís Mundet i Cerdán, 1997, "La Costa Brava ante los nuevos retos del turismo", Estudios Turísticos, núm. 133.

Enríquez Martínez, Mario, Maribel Osorio García, Marcelino Castillo Néchar, y Antonio Arellano Hernández, 2012, "Hacia una caracterización de la política turística”, Pasos, vol. 10, núm. 3.

Fayos-Solá, Eduardo, 2004, "Política turística en la era de la globalización”, Mediterráneo Económico, núm. 5 .

Fayos-Solá, Eduardo, 1996, “Tourism Policy: A Midsummer Night’s Dream?”, Tourism Management, vol. 17, núm. 6.

Ferrer, Aldo, 2010, El futuro de nuestro pasado. La economía argentina en su segundo centenario, Buenos Aires, Fondo de Cultura Económica.

Garay, Luis, y Gemma Cánoves, 2011, "Life Cycles, Stages and Tourism History: The Catalonia (Spain) Experience", Annals of Tourism Research, vol. 38, núm. 2.

Go, Frank M., y Ray Pine, 1995, Globalization Strategy in the Hotel Industry, Londres, Routledge.

González Reverté, Francesc, 2010. "Introducción a la gestión pública del turismo”, en Oriol Izard Miralbell (coord.), Gestión pública del turismo, España, uoc.

Gormsen, Ermann, 1981, “The Spatio-Temporal Development of International Tourism: Attempt a Centre-Perifery Model", en La Consommation d'espace par le Tourisme et sa Preservation, Aix-en-Provance, C.H.E.T.

Gourevitch, Peter, 2011, “La 'segunda imagen' invertida: los orígenes internacionales de las políticas domésticas”, en Jefatura de Gabinete de Ministros de la Nación (comp.), Lecturas sobre el Estado y las políticas públicas: Retomando el debate de ayer para fortalecer el actual, Buenos Aires, JGM.

Hall, Michael, 2011, "A Typology of Governance and its Implications for Tourism Policy Analysis", Journal of Sustainable Tourism, vol. 19, núms. 4-5. 
Hall, Michael, 2010, "Politics and Tourism: Interdependency and Implications in Understanding Change", en R. Butler, y W.Suntikul (eds.), Tourism and Political Change, Oxford, Goodfellow Publishers.

Hall, Michael, 1998, Tourism and Politics. Policy, Power and Place, Chichester, John Wiley $\&$ Son.

Higgins-Desbiolles, Freya, 2006, "More than an 'Industry': The Forgotten Power of Tourism as a Social Force”, Tourism Management, vol. 27, núm. 6.

Hillali, Mimoun, 2007, “Du tourisme et la géopolitique au Maghreb: Le cas du Maroc”, Hérodote, núm. 127, Francia.

Hjalager, Anne-Mette, 2007, "Stages in the Economic Globalization of Tourism", Annals of Tourism Research, vol. 34, núm. 2.

Ioannides, Dimitri, y Keith Debbage, 1997, "Post-Fordism and Flexibility: The Travel Industry Polyglot", Tourism Management, vol. 18, núm. 4.

Jefatura de Gabinete de Ministros, 2006, "El turismo como política de Estado en la República Argentina”, Observatorio de políticas públicas, Argentina, JGM.

Jenkins, C. L., 1980, “Tourism Policies in Developing Countries: A Critique”, International Journal of Tourism Management, vol. 1, núm. 1.

Jenkins, C. L., y B. M. Henry, 1982, "Government Involvement in Tourism in Developing Countries”, Annals of Tourism Research, vol. 9, núm. 4.

Kosters, M., 1984, “The Deficiencies of Tourism Science without Political Science: Comment on Richter", Annals of Tourism Research, núm. 11.

Lara, Alejandro (comp.), 2008, Cien años de turismo argentino, Buenos Aires, Proia.

Lash, Scout, y John Urry, 1987, The End of Organized Capitalism, Cambrigde, Polity Press.

Lickorish, Leonard, y Carson Jenkins, 2000, Una introducción al turismo, Madrid, Síntesis.

Magadán Díaz, Marta, y Jesús Rivas García, 2012, Estructura, economía y politica turística, Oviedo, Septem Ediciones.

Mair, Heather, 2006, "Global Restructuring and Local Responses: Investigating Rural Tourism Policy in Two Canadian Communities”, Current Issues in Tourism, vol. 9, núm. 1. 
Mantobani, J. M., 1997, "Notas sobre el problema de la creación de los primeros balnearios argentinos a fines del siglo XIX", Scripta Nova, núm. 11.

Matthews, Harry, y Linda Richter, 1991, "Political Science and Tourism", Annals of Tourism Research, núm. 18.

Ministerio de Turismo de la Nación (mintur), 2012, Anuario Estadístico de Turismo 2012, Buenos Aires.

Ministerio de Turismo de la Nación (MINTUR), 2011, Encuesta de Viajes y Turismo en Hogares (EVyTH). Subsecretaría de Desarrollo Turístico, Mintur.

Monfort Mir, Vicente, 2000, “La política turística: una aproximación”, Cuadernos de Turismo, núm. 6.

Organización Mundial del Turismo (омт), 2013, Compendium of Tourism Statistics dataset, [en línea], disponible en <http://mkt.unwto.org/es/barometer>, consulta del 25 de marzo 2013.

Organización Mundial Turismo (Омт), 1998, "Necesidad de intervención pública en el mercado turístico", Introducción al turismo, Madrid.

Organización Mundial del Turismo (омт), 1983, El marco de la responsabilidad del Estado en la gestión del turismo, омт, Asamblea General.

Owen, Charles, 1992, "Building a Relationship between Government and Tourism", Tourism Management, vol. 13, núm. 4.

Pastoriza, Elisa, 2011, La conquista de las vacaciones. Breve historia del turismo en la Argentina, Buenos Aires, Edhasa.

Pastoriza, Elisa, y Marcelo Pedetta, 2009, “'Lo que el pueblo necesita'. Turismo social y Peronismo. Argentina, 1945-1955”, Études Caribéennes, Francia.

Pearce, Douglas, 1991, Tourist Development, Nueva York, John Wiley \& Sons.

Piglia, Melina, 2008, "La incidencia del Touring Club Argentino y del Automóvil Club Argentino en la construcción del turismo como cuestión pública (1918-1929)", Revista Estudios y Perspectivas en Turismo, vol. 17, núm. 1.

Presidencia de la Nación, 2003, Politicas de Estado. Presidencia de la Nación, [en línea], consultado en <http://www.presidencia.gov.ar/>, consulta del 6 de agosto de 2013,

Rapoport, Mario, 2010. Las políticas económicas de la Argentina. Una breve historia, Buenos Aires, Booket. 
Richter, Linda, 1983, "Tourism Politics and Political Science. A Case of not so Benign Neglect”, Annals of Tourism Research, núm. 10.

Scatzanella, Eugenia, 1998, "El ocio peronista: vacaciones y 'turismo popular' en Argentina (1943-1955)", Entrepasados. Revista de Historia, núm. 14.

Schlüter, Regina, 2003, El turismo en la Argentina. Del balneario al campo, Buenos Aires, Centro de Investigaciones y Estudios Turísticos.

Scott, Noel, 2011, Tourism Policy: A Strategic Review, Oxford, Goodfellow.

Secretaría de Turismo de la Nación (SECTUR), 2008, Encuesta de Viajes y Turismo en Hogares (EVyTH). Subsecretaría de Desarrollo Turístico, Sectur.

SECTUR, 2012, "100 años de turismo", [en línea], disponible en <http://www.cienaniosdeturismo.gov.ar/pagina.asp?IdSeccion=11>, consulta del 8 de marzo de 2013.

Torrado, Susana, 2010, "Modelos de acumulación, regímenes de gobierno y estructura social", El costo social del ajuste (Argentina 1976-2002), Buenos Aires, Edhasa.

Velasco González, María, 2011, "La política turística. Una arena de acción autónoma”, Cuadernos de Turismo, núm. 27.

Velasco González, María, 2002, Sobre el turismo y la politica turistica. Conclusiones de la tesis doctoral: La politica turística: objeto, contenido e instrumentos. Evolución de la politica turística en la Organización Central del Estado: 1951-2000, España, Universidad Complutense.

Vernon, Jon, Stephen Essex, David Pinder, y Kaja Curry, 2005, "Collaborative Polymanking: Local Sustainable Projects”, Annals of Tourism Research, vol. 32, núm. 2.

Wallingre, Noemí, 2007a, Historia del turismo argentino, Buenos Aires, Ediciones Turísticas.

Wallingre, Noemí, 2007b, Retrospectiva y perspectiva del ordenamiento territorial para el desarrollo del turismo en la República Argentina, viII Jornadas Nacionales y II Simposio Internacional de Investigación Acción en Turismo, Posadas, Argentina.

Williams, Allan, y Gareth Shaw (eds.), 1988, Tourism and Economic Development. Western European experiences, Londres, Pinter Publishers.

Recibido el 29 de octubre de 2013. Aceptado el 24 de octubre de 2014. 